\title{
The Gut Microbiota and Human Health with an Emphasis on the Use of Microencapsulated Bacterial Cells
}

\author{
Satya Prakash, Catherine Tomaro-Duchesneau, Shyamali Saha, and Arielle Cantor \\ Biomedical Technology and Cell Therapy Research Laboratory, Departments of Biomedical Engineering and Physiology \\ and Artificial Cells and Organs Research Center, Faculty of Medicine, McGill University, 3775 University Street, Montreal, \\ QC, Canada H3A 2B4
}

Correspondence should be addressed to Satya Prakash, satya.prakash@mcgill.ca

Received 19 November 2010; Revised 16 February 2011; Accepted 11 April 2011

Academic Editor: Eric C. Martens

Copyright (C) 2011 Satya Prakash et al. This is an open access article distributed under the Creative Commons Attribution License, which permits unrestricted use, distribution, and reproduction in any medium, provided the original work is properly cited.

\begin{abstract}
The gut microbiota plays a crucial role in maintaining health. Alterations of the gut bacterial population have been associated with a number of diseases. Past and recent studies suggest that one can positively modify the contents of the gut microbiota by introducing prebiotics, probiotics, synbiotics, and other therapeutics. This paper focuses on probiotic modulation of the gut microbiota by their delivery to the lower gastrointestinal tract (GIT). There are numerous obstacles to overcome before microorganisms can be utilized as therapeutics. One important limitation is the delivery of viable cells to the lower GIT without a significant loss of cell viability and metabolic features through the harsh conditions of the upper GIT. Microencapsulation has been shown to overcome this, with various types of microcapsules available for resolving this limitation. This paper discusses the gut microbiota and its role in disease, with a focus on microencapsulated probiotics and their potentials and limitations.
\end{abstract}

\section{Introduction}

The gut microbiota, which resides in the gastrointestinal tract (GIT) and is also termed microflora, plays an important role in human health and disease. The GIT is comprised of the stomach, the duodenum, the jejunum, the ileum, the colon, the rectum, and the anal canal. The lower digestive tract, specifically the colon, is the primary site of importance for bacterial cell colonization; however, upper digestive tract microorganisms are also of importance. The bacterial population of the gut has been studied in diseases such as colon cancer, inflammatory bowel diseases (IBD), hypercholesterolemia, nonalcoholic fatty liver disease (NAFLD) and others. Certain bacterial populations, such as lactic acid bacteria, have been shown to positively influence health Hence, attempts to modify the microflora, towards those bacteria, for disease treatment and prevention should prove advantageous. For this purpose, prebiotics, probiotics, and synbiotics have been used. The delivery of viable probiotic bacteria is impeded by the harsh conditions of the upper GIT, hence, a vessel for delivering optimum cell viability to the lower GIT is required. Microcapsules can be used as a vehicle with the capability to protect the viability and activity of orally delivered bacterial cells through the upper GIT.

This paper will first give an overview of the gut microbiota and its main characteristics, focusing on its role in colon cancer, IBD, and hypercholesterolemia. Modulation of the gut microbiota to promote health will then be described through the use of probiotics, prebiotics, and synbiotics, with probiotics as a main focus. Microencapsulation and types of microcapsules will be described along with their success in the treatment and prevention of diseases. Finally, the paper will conclude with a discussion on this field's future.

\section{The Gastrointestinal Bacterial System}

The gut microbiota contains a broad spectrum of microorganisms, totalling $10^{13}$ to $10^{14}$ bacterial cells, but has not been completely explored as of yet [1]. The importance of the gut microflora is exemplified by the fact that the number of bacterial cells outnumbers human cells by a factor of ten [2]. The human intestinal habitat contains 300 to 500 different species of bacteria, varying significantly in content 


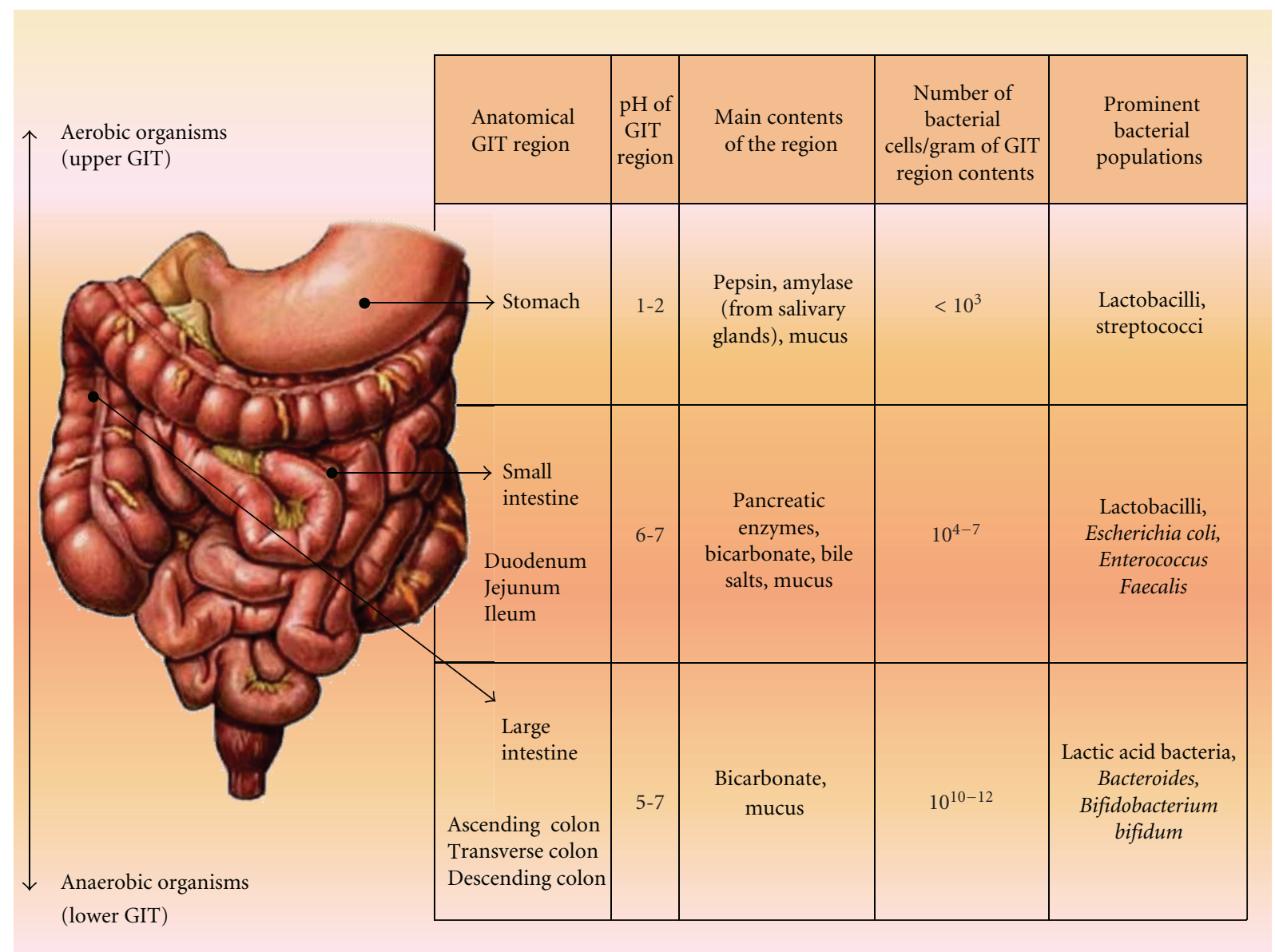

Figure 1: The GIT characteristics (oxygen distribution, $\mathrm{pH}$, bacterial populations, and bacterial cell counts) and the localization of the various gut bacterial populations, termed microbiota.

between individuals [3]. Most gut bacteria reside in the lower part of the digestive tract, in the large intestine, since the upper tract consists of high levels of acid, bile, and pancreatic secretions which are toxic to most microorganisms, as shown in Figure 1 [3]. Even though some bacterial species of the gut are potential pathogens, the constant interaction between the host and its microbes usually remains beneficial to the health of the host [4]. It has been demonstrated that the gut bacterial population plays an important role in their host's metabolism and energy consumption, especially in the digestion and absorption of nutrients $[1,5]$. The upper portion of the GIT, made up of the stomach and the duodenum, harbours very low numbers of microorganisms, with less than 1000 bacterial cells per gram of contents, with the predominant microorganisms present being Lactobacilli and Streptococci $[6,7]$. The relatively low number of microorganisms found in the upper digestive tract, although some are of great importance in human disease, can be explained by the presence of high levels of acid, bile, and pancreatic secretions, as aforementioned $[7,8]$. One important organism found in the stomach, which can withstand these harsh conditions, is Helicobacter pylori, a microorganism responsible for ulcers and stomach cancer [9]. There is also a phasic propulsive motor activity in the upper GIT which impedes any stable bacterial colonization [10]. Lower in the digestive tract are found the jejunum and the ileum where there is a gradual increase in the bacterial numbers from $10^{4}$ to approximately $10^{7}$ cells per gram of contents by the time the distal ileum is reached [7]. Once in the large intestine, the tract is heavily populated by anaerobes with up to $10^{12}$ cells per gram of luminal contents [10]. This paper focuses on the lower part of the digestive tract, due to its abundant bacterial population.

Bacteria are classified into genera and species based on their individual phenotypic and genotypic characteristics, with a number of different genera found actively residing in the human GIT. The dominant anaerobic genera are Bacteroides, Bifidobacterium, Eubacterium, Clostridium, Peptococcus, Peptostreptococcus, and Ruminococcus $[4,11]$. The main genera of facultative anaerobic bacteria are Escherichia, Enterobacter, Enterococcus, Klebsiella, Lactobacillus, and Proteus $[4,11]$. The proportion and numbers of these bacteria can vary, depending on a number of genetic and environmental factors, including disease state and one's food intake $[1,11-13]$. The main functions of the microflora were mostly elucidated by investigations with animals bred under germ-free conditions, with the functions broadly qualified as metabolic, trophic, and protective $[3,14,15]$. 
The gut microbiota has a significant impact on host metabolism, participating in microbial-mammalian co-metabolism. The microbiota is considered a multifunctional organ with metabolic capabilities that humans have not yet fully evolved into their own genomes [16]. It has the ability to break down indigestible plant polysaccharides, termed dietary fibers and also plays an important role in the biotransformation of conjugated bile acids, described in more detail later in this paper [17-20]. The importance of the gut microbiota in vitamin synthesis was demonstrated many years ago with the use of germ-free animals [21]. Experiments on a chick animal model demonstrated the synthesis of riboflavin, vitamin $B$, pantothenic acid, vitamin $\mathrm{B}_{12}$, folic acid, nicotinic acid, thiamine, and biotin by the gut microbiota [22]. Furthermore, Pseudomonas and Klebsiella sp., two resident organisms of the small intestine, were specifically shown to synthesize significant amounts of vitamin $B_{12}$ [23]. As described, the gut microbiota has extensive roles to play in normal human metabolism.

\section{The Gut Microbiota and Its Role in Human Health and Disease}

The gut microbiota has gained importance in disease aetiology and pathology, with emerging evidence demonstrating its role in disease $[1,24]$. A number of diseases have been associated with alterations of the gut microbiota, and if one can elucidate the exact link between the two one can begin to successfully treat and prevent these disorders through the modulation of the number and/or species of microorganisms present. Some disorders associated with the microflora include colon cancer, IBD, hypercholesterolemia and nonalcoholic fatty liver disease, among others [13, 24-28].

3.1. Role of the Gut Microbiota in Colon Cancer. Colorectal cancer is the second most common cause of cancer death in men and women [29]. Although the genetic mechanisms of colorectal cancer are well established, there are several environmental factors that have also been implicated in the development of sporadic colon carcinomas [3, 30]. Foods, such as processed meats, which contain high levels of dietary fat, have been associated with an increased risk of colon cancer development when compared to the risk associated with a high intake of fruits, vegetables, grains, and fish [30, 31]. It was proposed that the effect of diet could be mediated by changes in the composition of the colonic microflora such that the intestinal bacteria are responsible for the initiation of colon cancer $[3,13]$. Data shows that bacteria of the Bacteroides and Clostridium genera were associated with an increase in the incidence and growth rate of colonic tumors in tumor-induced animals, while genera such as Lactobacillus and Bifidobacterium (well-characterized bacteria predominantly used in therapeutic probiotic formulations) appeared to prevent tumorigenesis $[32,33]$. The properties of the colonic microflora make it a promising target for the development of a colon cancer therapeutic [34].

3.2. Inflammatory Bowel Disease and the Gut Microbiota. IBD, prominent in Western countries, is made up of a group of disorders that are characterized by a chronic and relapsing inflammation of the GIT [35]. The two most prominent forms of IBD are Crohn's Disease (CD) and ulcerative colitis (UC), with the bacterial flora as an important factor and contributor of the inflammation $[36,37]$. Sufferers of IBD have a higher bacterial attachment to gut epithelial surfaces when compared to that found in healthy individuals [38]. The link between intestinal mucosal inflammation and the resident bacteria has been further demonstrated, in vivo, using rats and mice treated with broad-spectrum antibiotics [39]. This treatment mitigates, although only temporarily, mucosal inflammation in animals with IBD, suggesting that the resident bacteria are causing the inflammation [39]. Furthermore, an overpopulation of the Bacteroides genera on the gut epithelium leads to an increased occurrence of transmural inflammatory lesions [3]. Early research demonstrated that the presence of Escherichia coli is linked to active UC and contributes to the development of inflammation [40]. E. coli has also been linked to CD, with the presence of specific adherent-invasive species found in the resected ileum of patients $[41,42]$. This effect appears to be species specific as only certain phylogenetic groups of $E$. coli were found to be more frequent in UC and CD patients when compared with healthy controls $[43,44]$. It is clear that the gut microflora plays an important role in IBD pathology and an efficient therapy is still required.

3.3. Gut Microbial System and Hypercholesterolemia. Hypercholesterolemia is a disorder whereby an individual demonstrates an elevated serum cholesterol level. For many decades now this disorder has been recognized as a significant risk factor associated with atherosclerosis and coronary heart disease [45]. Current treatment options to lower serum cholesterol levels involve the use of pharmacological agents such as statins which act by inhibiting HMG-CoA reductase, the rate-limiting enzyme of cholesterol biosynthesis [46]. Statins make up a group of compounds that are generally well tolerated but remain expensive and have significant side-effects, including gastrointestinal problems, such as diarrhoea, but may also include severe liver and skeletal abnormalities [47-49]. Bearing the potential significant consequences of hypercholesterolemia in mind, the importance of the gut microbiota in cholesterol metabolism and the pathogenesis of hypercholesterolemia, a new paradigm is suggested for the development of a successful treatment.

As early as 1959, research was performed to elucidate the role of the gut microbiota in cholesterol homeostasis with researchers demonstrating that germ-free rats, administered a diet without significant amounts of cholesterol, nonetheless showed higher serum-cholesterol values than control rats administered the same diet [50]. Several mechanisms have been proposed as methods by which the gut microbiota may modulate cholesterol levels within the host [51]. Recent developments have demonstrated that the composition of the microbiota and diet is directly correlated with cholesterol levels in vivo, specifically, the number of Bifidobacteria found in the gut is positively correlated with higher levels of high-density lipoprotein (HDL) [52-54]. In contrast, the number of Coriobacteriaceae is correlated with higher 
levels of non-HDL cholesterol [53]. Gut microbial activities influence lipid metabolism, bearing a significant impact on hypercholesterolemia, by the modification of bile acid metabolic patterns, by impacting the emulsification, absorption, and storage properties of bile acids and by influencing the lipoperoxidation through bile acid signalling properties [19]. With these facts in mind, the modulation of the gut microbiota could potentially decrease hypercholesterolemia in affected patients.

\section{Modulation of the Gut Microbiota for Human Health Benefits}

Past and current research has demonstrated that the gut microbiota plays an important role in the pathogenesis of a number of diseases. Certain bacteria, considered "good," such as Bifidobacteria and Lactobacilli, are shown to be correlated with a decrease in the occurrence of a number of disorders, suggesting that the targeted increase of these beneficial bacteria could decrease the incidence and severity of prominent diseases. The colonic delivery of prebiotics and probiotics are methods that have been successfully used to modify the gut microbiota. Antibiotics can prove beneficial in short-term use but their prolonged use may result in significant side-effects. An important concern is the development of bacterial resistance which reduces the effectiveness of the therapy and further predisposes the patient to life-threatening illnesses caused by potential pathogens with increased resistance to the antibiotic.

Current research focuses on prebiotics, probiotics, and a combination of both, termed synbiotics for modulating the gut microbiota. The Food and Agriculture Organization of the United Nations defines a prebiotic as a "non-viable food component that confers a health benefit on the host, associated with a modulation of the microbiota" [55]. Prebiotic molecules consist of naturally occurring or synthetic sugars used by certain colonic bacteria, especially Bifidobacteria, as a carbon source for growth and metabolism [56]. Numerous prebiotics have demonstrated their beneficial effects on disease through modulators of the gut microbiota [57-61]. Prebiotic delivery nonspecifically increases the number of "good bacteria" not acting at the species level, which may be important in some disease states. On the other hand, probiotics are a method by which the gut microbiota can be specifically modulated for an individual to reestablish and maintain a healthy state.

4.1. Modulation of the Gut Microbiota by Probiotics Can Promote Human Health. The FAO and WHO define probiotics as "live microorganisms which, when administered in adequate amounts, confer a health benefit on the host" [62]. Probiotics are inexpensive, safe, free of long-term negative side-effects, and have already demonstrated beneficial effects for treating immunological, digestive, and respiratory diseases [62]. Furthermore, these are naturally occurring organisms found in foods such as milk and yoghurt and, so, are widely accepted by the general public. The most common types of probiotic microorganisms are the lactic acid bacteria, important components of the healthy gut microbiota and regarded as safe by the American FDA [63]. Other microorganisms occasionally used as probiotics are yeasts and filamentous fungi [63]. In this section, we describe the use of probiotics on colorectal cancer, IBD, hypercholesterolemia and NAFLD.

Probiotics have been proposed and investigated as a potential treatment/prevention method for colorectal cancer. Early studies demonstrated that 1,2-dimethylhydrazine(DMH-) induced colon cancer in rats showed a decrease in mortality rate if the test animals were fed Streptococcus thermophilus-fermented skim milk [94]. Another research group demonstrated that Lactobacillus rhamnosus GG, in lyophilized form incorporated in a high-fat diet, was effective at reducing tumor incidence in the rat $\mathrm{DMH}$ colon cancer model [95]. Studies using Bifidobacterium longum also demonstrated an inhibition of carcinogen-induced colon cancers and precursor lesions [96, 97]. Additional studies demonstrate a reduction of colon tumorigenesis markers following the incorporation of Lactobacillus acidophilus in a high-fat control diet in $\mathrm{DMH}$ colon cancer rats [98]. The probiotics are suggested to achieve a protective effect by interacting with the carcinogen(s) in the intestinal lumen (in the case of the DMH rat model, interaction with the DMH metabolites azoxymethane or methylazoxymethane) leading to a decrease in the potency/availability of the carcinogenic compound [97, 98].

Probiotics have also been investigated as a method of treatment for IBD. A trial in ulcerative colitis (UC) patients was performed to study the effect of the delivery of an oral probiotic capsule on the remission of the disorder [99]. The probiotic Bifidobacteria were administered following treatment with an UC standard therapy [99]. It was demonstrated that $93.3 \%$ of the patients in the control group suffered a disease relapse compared to only $20 \%$ of the patients administered the probiotic capsule [99]. A significant reduction in inflammation was also observed in the treatment group when compared to the control group [99]. Another study demonstrated the use of Faecalibacterium prausnitzii as a probiotic for treating Crohn's Disease (CD) [36]. F. prausnitizii and its supernatant were both found to have anti-inflammatory effects in vitro using peripheral blood mononuclear and colon adenocarcinoma cells and in vivo in a mouse model of induced colitis [36]. A number of other studies related to the effects of probiotics on the prevention and the treatment of IBD, described in another review, have been done, with varying success [100].

Early studies suggest that probiotic bacteria may have a beneficial effect on hypercholesterolemic patients, by decreasing blood lipid levels [101]. A study was undertaken with hypercholesterolemic mice administered low levels of the probiotic Lactobacillus reuteri for a week [101]. The mice demonstrated a decrease in cholesterol and triglyceride levels and an increase in the HDL:LDL ratio [101]. A study was also performed with hyperlipidemic patients who were administered the probiotic Lactobacillus sporogenes over a three-month period [102]. Following treatment, these patients showed, on average, a $32 \%$ reduction in total cholesterol levels accompanied with a $35 \%$ reduction in 

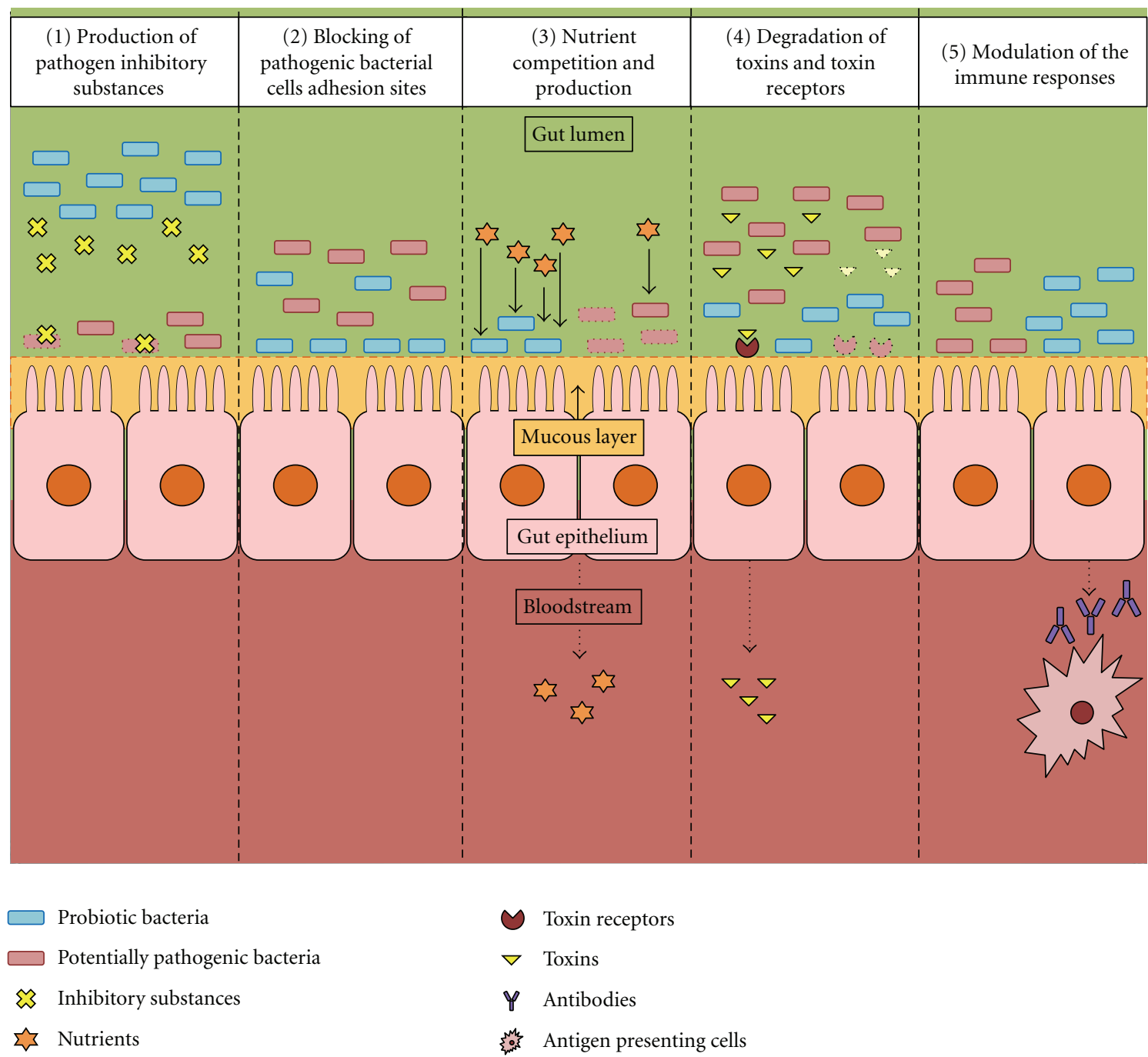

FIGURE 2: Pathways by which a probiotic can positively influence human health. They can influence human health by (1) production of pathogen inhibitory substances; (2) blocking of pathogenic bacteria adhesion sites; (3) nutrient competition and production; (4) degradation of toxins and toxin receptors; (5) modulation of innate immune responses.

LDL [102]. Studies have also demonstrated that the delivery of certain strains of Lactobacilli can alleviate symptoms associated with IBD $[103,104]$.

Probiotics have also been proposed as a potential treatment option for NAFLD because of their modulating effect on the gut flora that could influence the gut-liver axis towards a healthy state. NAFLD is characterized by the release of inflammatory cytokines and commensal bacteria have been shown to provoke anti-inflammatory responses from the gut epithelia, suggesting a mechanism of action to treat the disease [105]. Probiotics can have an inhibitory impact on the development of NAFLD by a number of mechanisms: competitive inhibition of pathogenic bacterial strains, alteration of the inflammatory effects of pathogenic strains through changes in cytokine signalling, improvement of the function of the epithelial barrier and direct decreases of proinflammatory cytokines, including TNF- $\alpha$ [105]. VSL\#3 is a high-potency medical food probiotic made up of a number of different bacterial strains [106]. These strains make up 450 billion live lactic acid bacteria per packet: Bifdobacterium breve, Bifidobacterium longum, Bifidobacterium infantis, Lactobacillus acidophilus, Lactobacillus plantarum, Lactobacillus paracasei, Lactobacillus bulgaricus, and Streptococcus thermophilus [106]. This combination, in both murine and human trials, demonstrated all of the mechanisms described as potential beneficial targets for the treatment of NAFLD [107]. Murine models of acute liver injury have also shown a decrease in hepatic injury following the administration of various Lactobacillus and Bifidobacterium species [108-110].

There are a number of mechanisms by which probiotics could be exerting their beneficial effects, as shown in Figure 2. The mechanisms include (1) by the production of pathogen inhibitory substances; (2) by the blocking of pathogenic bacteria adhesion sites; (3) by nutrient competition and production; (4) by the degradation of toxins and toxin receptors; (5) by the modulation of immune responses [104]. 


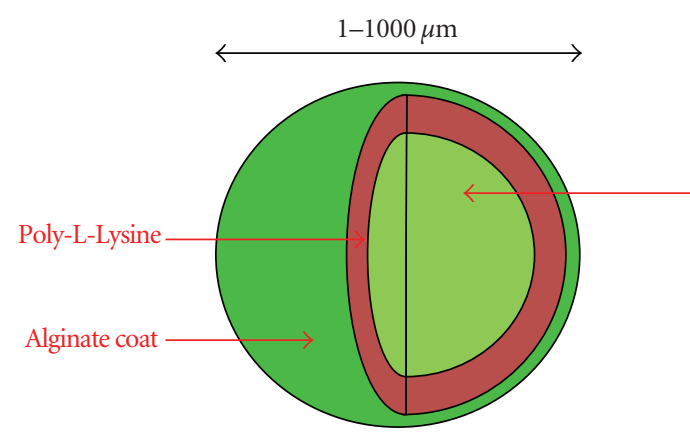

(a)

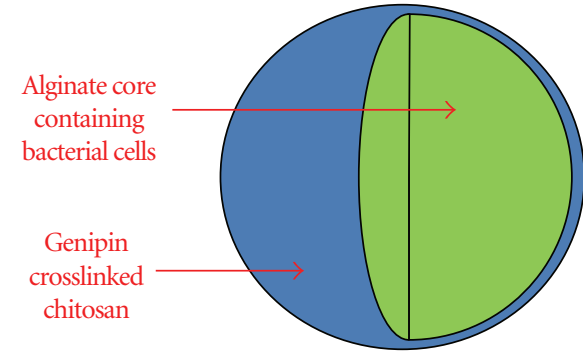

(b)

FIgure 3: The concept of microcapsules for probiotic delivery. (a) Alginate-Poly-L-Lysine (APA) and (b) Genipin Crosslinked Alginate Chitosan (GCAC) microcapsules.

4.2. System for Delivering Probiotics to the GIT. Probiotics must be delivered to the target sites in sufficient number and metabolic active phase to be effective. Currently available probiotic formulations are excellent but have serious limitations. One of the major limitations is the delivery of probiotics to the lower GIT, with the presence of acids and bile greatly hindering the viability of the probiotics as they travel through the gut (specifically the acidic environment of the stomach). A delivery system is, hence, required to surpass this obstacle. Another complication is the presence of an immune system which can be induced and potentially attack the delivered cells. Hence, a method is required to protect the probiotic cells while maintaining high levels of probiotic viability and activity when delivered in the GIT. There are many methods available, each with its own limitations. This paper introduces microencapsulation and discusses its potentials and limitations in bacterial cell delivery to the GIT.

\section{Microencapsulation and Delivery of Probiotics}

Microencapsulation is a method defined as the "entrapment of a compound or a system inside a dispersed material for its immobilization, protection, controlled release, structuration and functionalization" [111]. There exists a great variety of microcapsules which can differ in size, composition, and function, depending on the final goal of the encapsulated product. Microcapsules can be used to entrap all sorts of substances: solids, liquids, drugs, proteins, bacterial cells, stem cells, and so forth [112-114]. With such a range of substances that can be entrapped, microcapsules can have an assortment of objectives and applications, whether for drug delivery, enzyme retrieval, artificial cell and artificial organ delivery or, as described in this review, for the delivery of live probiotic bacteria.

There are a number of microcapsule delivery systems that have been proposed for the oral delivery of live bacterial cells, as detailed in Table 1. Sun and Griffiths investigated the use of acid-stable beads made of gellan and xanthan gum for the immobilization of Bifidobacterium [84]. The research group demonstrated that immobilized cells survived significantly better than free cells after refrigeration in pasteurized yogurt for a period of 5 weeks [84]. One common encapsulation method, for viable cell immobilization, utilizes calcium alginate as a polymer [115]. However, one prominent difficulty encountered with the use of alginate beads is that these, alone, are not acid resistant and upon exposure to the low $\mathrm{pH}$ conditions encountered in the stomach, display significant shrinkage and a decrease in mechanical strength [64]. A number of methods utilizing polymer cross-linking have been suggested, including formulations using carrageenan, alginate-poly-L-lysine, starch polyanhydrides, polymethacrylates, and enteric coated polymers [116]. Microencapsulation methods are still being developed and optimized to allow for increased gastrointestinal survival and immunoprotection. One newly developed type of microcapsule that shows promising results in terms of mechanical stability and $\mathrm{pH}$ resistance is the genipincrosslinked-alginate-chitosan (GCAC) microcapsule, shown in Figure 3 [87, 117].

One of the most commonly utilized and characterized formulations for microencapsulation is the alginate-polyL-lysine-alginate (APA) microcapsule [118]. This type of microcapsule has been used for many applications including drug, stem cell, and bacterial cell delivery. This method relies on a polyelectrolyte complexation mechanism for the association of the polymers, alginate and poly-L-lysine (PLL). Alginate is a naturally occurring biocompatible polymer, extracted from brown algae, that is increasingly being used in the biotechnology industry for a wide range of applications [119]. Alginate is an unbranched polysaccharide which contains $1,4^{\prime}$-linked $\beta$-D-mannuronic acid and $\alpha$-L-guluronic acid blocks which are interdispersed with regions of the alternating structure, $\beta$-L-mannuronic acid- $\alpha$-L-guluronic acid blocks [120]. PLL is a polypeptide made up of the amino acid L-lysine that is available in a variable number of chain lengths, determined by its molecular weight. It is a polycationic polymer that can be used during the coating step of microencapsulation. The addition of this polymer leads to the formation of a capsule membrane that provides selective permeability and immunoprotection. The alginate bead could not withstand the harsh conditions of the GIT in the absence of PLL, which provides it with an increased mechanical stability. 
TABLE 1: Types of microcapsules available for the targeted delivery of probiotic bacteria.

\begin{tabular}{|c|c|c|}
\hline Types of Microcapsules & Bacteria & Reference(s) \\
\hline Alginate Beads & $\begin{array}{l}\text { L. rhamnosus } \\
\text { B. longum } \\
\text { L. salivarius } \\
\text { L. plantarum } \\
\text { L. acidophilus } \\
\text { L. paracasei } \\
\text { L. casei } \\
\text { B. lactis } \\
\text { L. reuteri }\end{array}$ & {$[64-70]$} \\
\hline $\begin{array}{l}\text { Alginate-cellulose } \\
\text { acetate phthalate }\end{array}$ & $\begin{array}{l}\text { B. lactis } \\
\text { L. acidophilus }\end{array}$ & {$[71]$} \\
\hline Alginate-chitosan & $\begin{array}{l}\text { B. animalis subsp. lactis } \\
\text { L. bulgaricus }\end{array}$ & {$[72,73]$} \\
\hline $\begin{array}{l}\text { Alginate-chitosan-Acryl- } \\
\text { Eze }\end{array}$ & B. animalis subsp. lactis & {$[72]$} \\
\hline $\begin{array}{l}\text { Alginate-chitosan- } \\
\text { alginate }\end{array}$ & $\begin{array}{l}\text { B. bifidum } \\
\text { L. casei }\end{array}$ & {$[64]$} \\
\hline $\begin{array}{l}\text { Alginate-chitosan- } \\
\text { Sureteric }\end{array}$ & B. animalis subsp. lactis & {$[72]$} \\
\hline Alginate-coated gelatin & $\begin{array}{l}\text { B. adolescentis } \\
\text { B. pseudolongum }\end{array}$ & {$[74]$} \\
\hline $\begin{array}{l}\text { Alginate-poly-L-lysine- } \\
\text { alginate }\end{array}$ & $\begin{array}{l}\text { B. bifidum } \\
\text { L. reuteri } \\
\text { L. casei } \\
\end{array}$ & {$[64,75]$} \\
\hline Alginate-starch & $\begin{array}{l}\text { L. acidophilus } \\
\text { B. lactis } \\
\text { B. infantis } \\
\text { L. casei }\end{array}$ & {$[76-78]$} \\
\hline $\begin{array}{l}\text { Gelatin-gum } \\
\text { arabic-soluble starch }\end{array}$ & $\begin{array}{l}\text { B. infantis } \\
\text { B. longum }\end{array}$ & {$[79-81]$} \\
\hline $\begin{array}{l}\text { Gelatin-toluene-2-4- } \\
\text { diisocyanate }\end{array}$ & L. lactis & {$[82]$} \\
\hline Gellan-alginate & B. bifidum & {$[83]$} \\
\hline Gellan-xanthan & $\begin{array}{l}\text { B. adolescentis } \\
\text { B. bifidum } \\
\text { B. breve } \\
\text { B. infantis } \\
\text { B. lactis } \\
\text { B. longum } \\
\end{array}$ & [84-86] \\
\hline $\begin{array}{l}\text { Genipin-crosslinked- } \\
\text { alginate-chitosan }\end{array}$ & L. plantarum & {$[87]$} \\
\hline Pectin-casein & $\begin{array}{l}\text { B. lactis } \\
\text { L. acidophilus }\end{array}$ & {$[88]$} \\
\hline $\begin{array}{l}\text { Potato starch } \\
\text { granules-amylose }\end{array}$ & B. longum & [89] \\
\hline Whey protein & $\begin{array}{l}\text { B. breve } \\
\text { B. longum } \\
\text { L. rhamnosus }\end{array}$ & {$[90,91]$} \\
\hline$\kappa$-carageenan & $\begin{array}{l}\text { B. longum } \\
\text { S. thermophilus } \\
\text { L. bulgaricus } \\
\text { S. lactis }\end{array}$ & {$[92,93]$} \\
\hline
\end{tabular}

There are a number of different methods used to fabricate microcapsules. The microencapsulation technique employed is determined by the type and the size of microcapsules one wants to obtain. The characteristics of the microcapsule must also take into consideration the function that the microcapsule will ultimately undertake. There are generally three main stages to the process of microencapsulation. The first step is the incorporation of the ingredients into a solution by mixing or dispersion, to make up the core of the microcapsule. This is then followed by mechanical operations, such as spraying or emulsification, to form the droplets. The final step of microencapsulation involves product stabilization through coating, followed by a number of physical or chemical processes [111]. Each step of microencapsulation can be optimized according to the desired characteristics of the final formulation.

\section{Microencapsulated Probiotics}

There has been strong interest in the field of microencapsulated probiotics. Research has shown that microencapsulated probiotics keep their viability better than free cells under stress in GIT deliveries. Research into the applications of microencapsulated probiotics is also ongoing, with promising results for the eventual treatment of a number of disorders, described in the following section.

6.1. Microencapsulated Probiotics and Colon Cancer. The potential antitumorigenic properties of a microencapsulated formulation of L. acidophilus were studied in Min (multiple intestinal neoplasia) mice carrying a germline $A p c$ mutation which spontaneously develop numerous pretumoric intestinal neoplasms [29]. The mice were gavaged APA microcapsules of $L$. acidophilus over a period of 12 weeks followed by the enumeration, the classification and the histopathology of adenomas [29]. Unfortunately, no statistically significant difference was observed between the treatment and control group in terms of the number of large intestinal (colonic) adenomas [29]. On a more positive note, there was a statistical difference between the control and treatment groups following analysis of the small intestine number of adenomas and gastrointestinal intraepithelial neoplasias [29]. These preliminary results suggest that microencapsulated probiotic bacteria could have a role in the development of a successful colon cancer therapeutic.

6.2. Microencapsulated Probiotics for Use in Cardiovascular Diseases. Recently, microcapsules containing bacterial cells have been developed as a cholesterol lowering therapy. Early research has demonstrated that certain Lactobacilli have a bile salt hydrolase (BSH) enzyme which can contribute to a significant cholesterol lowering effect in vivo in cardiovascular diseases [121]. This enzyme contributes to the deconjugation of bile salts in the intestine [121]. The oral delivery of Lactobacillus has, therefore, emerged as a potential mechanism for inducing cholesterol lowering. Martoni et al. demonstrated that microencapsulated $\mathrm{BSH}$-active bacteria are able to survive in a simulated human gastrointestinal model while maintaining cell viability and enzyme activity, which would not be possible with the direct delivery of nonmicroencapsulated bacterial cells [75]. 
Another microencapsulated probiotic Lactobacillus demonstrated cholesterol lowering capabilities in hypercholesterolemic animals, albeit with a different mechanism of action involving a feruloyl esterase enzyme [122]. Lactobacillus fermentum, a feruloyl esterase active bacterium, was microencapsulated and delivered to hypercholesterolemic hamsters twice daily by oral gavage, for a period of 18 weeks [122]. Following treatment, hamster serum cholesterol, LDL cholesterol, and the atherogenic index were $21.36 \%, 31.40 \%$, and $32.59 \%$ lower, respectively, in the treatment group when compared to the control group [122]. Histological studies were also performed and demonstrated that the microencapsulated probiotic reduced the progression of atherosclerotic lesions in the test animals [122]. This probiotic formulation was hence shown to be effective at managing excessive serum cholesterol and triglyceride levels [122]. With these results, the microencapsulation of probiotics is very promising for the development of a cholesterol-lowering therapeutic in cardiovascular diseases.

Microencapsulation has the potential to be useful in other disease applications. It has been shown that, to be effective at reducing colon tumorigenesis, therapeutic probiotic microorganisms must remain viable in vivo [123]. The same study that demonstrated that the administration of $L$. acidophilus had an inhibitory effect on colon tumorigenesis showed that the amount of probiotic colonization of the GIT is directly linked to the rate of inhibition of tumorigenesis [98]. Since viability is vital to the mechanism of action of the probiotic, it is crucial to realize that, of the bacteria ingested, only $1 \%$ survive the gastric transit, limiting the overall therapeutic effect of any orally delivered bacterial formulation [124]. With unprotected probiotic formulations already demonstrating therapeutic potential, microencapsulation could prove beneficial in increasing efficacy.

\section{Challenges and Future Outlooks}

The gut microbiota is a complex system that has been shown to influence health. Although probiotics, prebiotics, and synbiotics have shown great potential for the treatment of a number of disorders, there are still a number of challenges that remain to be addressed before they can be successfully used to treat/prevent disorders. Microencapsulation has provided a significant advancement in the field, allowing for the delivery of a greater number of viable bacteria to the GIT. However, a number of issues concerning the formulation of a microencapsulated probiotic still need to be addressed before a successful product can be developed. The process and methods for microencapsulation require further investigations and optimization. As aforementioned, there are a number of microencapsulation types being employed, each varying in efficiency and application. Furthermore, the industry scale production of microencapsulated probiotics, at a cost-effective level, and investigation of formulation stability, cell viability and retention of metabolic activity of the encapsulated bacterial cells requires further development for specific bacterial strains and diseases.

Most of the probiotics are strain specific, they therefore must be developed and characterised in vitro and evaluated for their suitability and efficacy in proper animal models and human clinical trials. Furthermore, a specific mechanism of action must be developed for each application so that an evidence-based probiotic formulation can be designed that can potentially compete with well-articulated and welldeveloped drug formulations. The elucidation of the mechanism of action of the probiotic would allow for a better selection process. As described before, the administration of bacteria from the same species but of different strains resulted in noncomparable effects, further emphasizing the importance of mechanistic studies as part of the probiotic selection process. The variability in experimental design poses a great challenge in probiotic research that must be addressed properly. Since the compositions of the gut microflora are not identical, there can be contradicting results as to the beneficial effect of probiotics on the microbiota of the GIT. This composition variability also gives rise to potential difficulties in terms of the use of animal models for the investigation of probiotic formulations. A targeted welldefined formulation should be developed in which microencapsulation will play a critical role.

There are excellent trials available that demonstrate the efficacy of these formulations but safety is an issue that remains to be investigated. As mentioned earlier, rigorous in vitro and in vivo animal and human clinical studies are needed to demonstrate the efficacy and the long-term safety of microencapsulated and other probiotic formulations. Nevertheless, the literature suggests that probiotics will lead to efficient therapeutic formulations for the treatment and/or prevention of a number of animal and human health disorders.

\section{Acknowledgments}

The authors would like to acknowledge the Canadian Institute of Health Research (CIHR) Grant (MPO 64308) and grants from Micropharma to Dr. S. Prakash, the support of the Industrial Innovation Scholarship (IIS) BMP Innovation-NSERC, FQRNT and Micropharma Limited to C. T. Duchesneau, and the NSERC Undergraduate Student Research Award to Arielle Cantor.

\section{References}

[1] P. D. Cani, "The role of the gut microbiota in energy metabolism and metabolic disease," Current Pharmaceutical Design, vol. 15, no. 13, pp. 1546-1558, 2009.

[2] P. J. Turnbaugh, R. E. Ley, M. Hamady, C. M. Fraser-Liggett, R. Knight, and J. I. Gordon, "The human microbiome project," Nature, vol. 449, no. 7164, pp. 804-810, 2007.

[3] F. Guarner and J. R. Malagelada, "Gut flora in health and disease," The Lancet, vol. 361, no. 9356, pp. 512-519, 2003.

[4] S. Salminen, C. Bouley, M. C. Boutron et al., "Functional food science and gastrointestinal physiology and function," British Journal of Nutrition, vol. 80, supplement 1, pp. S147S171, 1998.

[5] H. Tilg, A. R. Moschen, and A. Kaser, "Obesity and the microbiota," Gastroenterology, vol. 136, no. 5, pp. 1476-1483, 2009. 
[6] J. Dicksved, M. Lindberg, M. Rosenquist, H. Enroth, J. K. Jansson, and L. Engstrand, "Molecular characterization of the stomach microbiota in patients with gastric cancer and in controls," Journal of Medical Microbiology, vol. 58, no. 4, pp. 509-516, 2009.

[7] F. Guarner, A. G. Khan, J. Garisch et al., Probiotics and prebiotics, 2008.

[8] I. Mainville, Y. Arcand, and E. R. Farnworth, "A dynamic model that simulates the human upper gastrointestinal tract for the study of probiotics," International Journal of Food Microbiology, vol. 99, no. 3, pp. 287-296, 2005.

[9] C. Montecucco and R. Rappuoli, "Living dangerously: how helicobacter pylori survives in the human stomach," Nature Reviews Molecular Cell Biology, vol. 2, no. 6, pp. 457-466, 2001.

[10] F. Guarner, "Enteric flora in health and disease," Digestion, vol. 73, supplement 1, pp. 5-12, 2006.

[11] B. P. Willing, J. Dicksved, J. Halfvarson et al., "A pyrosequencing study in twins shows that gastrointestinal microbial profiles vary with inflammatory bowel disease phenotypes," Gastroenterology, vol. 139, no. 6, pp. 1844-1854, 2010.

[12] E. Culligan, C. Hill, and R. Sleator, "Probiotics and gastrointestinal disease: successes, problems and future prospects," Gut Pathogens, vol. 1, no. 19, pp. 1-12, 2009.

[13] C. D. Davis and J. A. Milner, "Gastrointestinal microflora, food components and colon cancer prevention," Journal of Nutritional Biochemistry, vol. 20, no. 10, pp. 743-752, 2009.

[14] C. Vael and K. Desager, "The importance of the development of the intestinal microbiota in infancy," Current Opinion in Pediatrics, vol. 21, no. 6, pp. 794-800, 2009.

[15] P. G. Falk, L. V. Hooper, T. Midtvedt, and J. I. Gordon, "Creating and maintaining the gastrointestinal ecosystem: what we know and need to know from gnotobiology," Microbiology and Molecular Biology Reviews, vol. 62, no. 4, pp. 1157-1170, 1998.

[16] J. Xu and J. I. Gordon, "Honor thy symbionts," Proceedings of the National Academy of Sciences of the United States of America, vol. 100, no. 18, pp. 10452-10459, 2003.

[17] L. V. Hooper, T. Midvedt, and J. I. Gordon, "How hostmicrobial interactions shape the nutrient environment of the mammalian intestine," Annual Review of Nutrition, vol. 22, no. 1, pp. 283-307, 2002.

[18] J. M. Campbell, G. C. Fahey, and B. W. Wolf, "Selected indigestible oligosaccharides affect large bowel mass, cecal and fecal short-chain fatty acids, $\mathrm{pH}$ and microflora in rats," Journal of Nutrition, vol. 127, no. 1, pp. 130-136, 1997.

[19] F. P. Martin, M. E. Dumas, Y. Wang et al., "A top-down systems biology view of microbiome-mammalian metabolic interactions in a mouse model," Molecular Systems Biology, vol. 3, 2007.

[20] P. B. Hylemon and J. Harder, "Biotransformation of monoterpenes, bile acids, and other isoprenoids in anaerobic ecosystems," FEMS Microbiology Reviews, vol. 22, no. 5, pp. 475-488, 1998.

[21] O. Mickelsen, "Intestinal synthesis of vitamins in the nonruminant," Vitamins and Hormones, vol. 14, pp. 1-95, 1956.

[22] M. E. Coates, J. E. Ford, and G. F. Harrison, "Intestinal synthesis of vitamins of the B complex in chicks," British Journal of Nutrition, vol. 22, no. 3, pp. 493-500, 1968.

[23] M. J. Albert, V. I. Mathan, and S. J. Baker, "Vitamin $B_{12}$ synthesis by human small intestinal bacteria," Nature, vol. 283, no. 5749, pp. 781-782, 1980.

[24] P. D. Cani and N. M. Delzenne, "Interplay between obesity and associated metabolic disorders: new insights into the gut microbiota," Current Opinion in Pharmacology, vol. 9, no. 6, pp. 737-743, 2009.

[25] N. M. Delzenne and P. D. Cani, "Nutritional modulation of gut microbiota in the context of obesity and insulin resistance: potential interest of prebiotics," International Dairy Journal, vol. 20, no. 4, pp. 277-280, 2010.

[26] M. G. Gareau, P. M. Sherman, and W. A. Walker, "Probiotics and the gut microbiota in intestinal health and disease," Nature Reviews Gastroenterology and Hepatology, vol. 7, no. 9, pp. 503-514, 2010.

[27] S. W. Gratz, H. Mykkanen, and H. S. El-Nezami, "Probiotics and gut health: a special focus on liver diseases," World Journal of Gastroenterology, vol. 16, no. 4, pp. 403-410, 2010.

[28] P. D. Scanlan, F. Shanahan, Y. Clune et al., "Cultureindependent analysis of the gut microbiota in colorectal cancer and polyposis," Environmental Microbiology, vol. 10, no. 3, pp. 789-798, 2008.

[29] A. M. Urbanska, J. Bhathena, C. Martoni, and S. Prakash, "Estimation of the potential antitumor activity of microencapsulated Lactobacillus acidophilus yogurt formulation in the attenuation of tumorigenesis in $\operatorname{Apc}(\mathrm{Min} /+)$ mice," Digestive Diseases and Sciences, vol. 54, no. 2, pp. 264-273, 2009.

[30] H. L. Newmark, K. Yang, N. Kurihara, K. Fan, L. H. Augenlicht, and M. Lipkin, "Western-style diet-induced colonic tumors and their modulation by calcium and vitamin $\mathrm{D}$ in $\mathrm{C} 57 \mathrm{Bl} / 6$ mice: a preclinical model for human sporadic colon cancer," Carcinogenesis, vol. 30, no. 1, pp. 88-92, 2009.

[31] S. A. Bingham, "Meat or wheat for the next millennium? Plenary lecture. High-meat diets and cancer risk," Proceedings of the Nutrition Society, vol. 58, no. 2, pp. 243-248, 1999.

[32] L. O’Mahony, M. Feeney, S. O'Halloran et al., "Probiotic impact on microbial flora, inflammation and tumour development in IL-10 knockout mice," Alimentary Pharmacology and Therapeutics, vol. 15, no. 8, pp. 1219-1225, 2001.

[33] H. Horie, K. Kanazawa, M. Okada, S. Narushima, K. Itoh, and A. Terada, "Effects of intestinal bacteria on the development of colonic neoplasm: an experimental study," European Journal of Cancer Prevention, vol. 8, no. 3, pp. 237245, 1999.

[34] D. H. Roukos, C. Katsios, and T. Liakakos, "Genotypephenotype map and molecular networks: a promising solution in overcoming colorectal cancer resistance to targeted treatment," Expert Review of Molecular Diagnostics, vol. 10, no. 5, pp. 541-545, 2010.

[35] E. V. Loftus, "Clinical epidemiology of inflammatory bowel disease: incidence, prevalence, and environmental influences," Gastroenterology, vol. 126, no. 6, pp. 1504-1517, 2004.

[36] H. Sokol, B. Pigneur, L. Watterlot et al., "Faecalibacterium prausnitzii is an anti-inflammatory commensal bacterium identified by gut microbiota analysis of Crohn disease patients," Proceedings of the National Academy of Sciences of the United States of America, vol. 105, no. 43, pp. 1673116736, 2008.

[37] F. Shanahan, "Inflammatory bowel disease: immunodiagnostics, immunotherapeutics, and ecotherapeutics," Gastroenterology, vol. 120, no. 3, pp. 622-635, 2001.

[38] A. Swidsinski, A. Ladhoff, A. Pernthaler et al., "Mucosal flora in inflammatory bowel disease," Gastroenterology, vol. 122, no. 1, pp. 44-54, 2002.

[39] S. Videla, J. Vilaseca, F. Guarner et al., "Role of intestinal microflora in chronic inflammation and ulceration of the rat colon," Gut, vol. 35, no. 8, pp. 1090-1097, 1994. 
[40] M. E. Cooke, S. P. Ewins, J. Hywel-Jones, and J. E. LennardJones, "Properties of strains of Escherichia coli carried in different phases of ulcerative colitis," Gut, vol. 15, no. 2, pp. 143-146, 1974.

[41] A. Darfeuille-Michard, C. Neut, N. Barnich et al., "Presence of adherent Escherichia coli strains in ileal mucosa of patients with Crohn's disease," Gastroenterology, vol. 115, no. 6, pp. 1405-1413, 1998.

[42] A. Darfeuille-Michaud, J. Boudeau, P. Bulois et al., "High prevalence of adherent-invasive Escherichia coli associated with ileal mucosa in Crohn's disease," Gastroenterology, vol. 127, no. 2, pp. 412-421, 2004.

[43] R. Kotlowski, C. N. Bernstein, S. Sepehri, and D. O. Krause, "High prevalence of Escherichia coli belonging to the B2+D phylogenetic group in inflammatory bowel disease," Gut, vol. 56, no. 5, pp. 669-675, 2007.

[44] A. Petersen, E. Nielsen, E. Litrup, J. Brynskov, H. Mirsepasi, and K. Krogfelt, "A phylogenetic group of Escherichia coli associated with active left-sided inflammatory bowel disease," BMC Microbiology, vol. 9, no. 1, article 171, 2009.

[45] D. P. Barr, E. M. Russ, and H. A. Eder, "Protein-lipid relationships in human plasma. II. In atherosclerosis and related conditions," The American Journal of Medicine, vol. 11, no. 4, pp. 480-493, 1951.

[46] A. Patel, R. Singhania, A. Pandey, and S. Chincholkar, "Probiotic bile salt hydrolase: current developments and perspectives," Applied Biochemistry and Biotechnology, vol. 162, no. 1, pp. 166-180, 2010.

[47] V. G. Athyros, K. Tziomalos, A. Karagiannis, and D. P. Mikhailidis, "Atorvastatin: safety and tolerability," Expert Opinion on Drug Safety, vol. 9, no. 4, pp. 667-674, 2010.

[48] K. Toutouzas, M. Drakopoulou, I. Skoumas, and C. Stefanadis, "Advancing therapy for hypercholesterolemia," Expert Opinion on Pharmacotherapy, vol. 11, no. 10, pp. 1659-1672, 2010.

[49] D. W. Erkelens, M. G. A. Baggen, J. J. van Doormaal, M. Kettner, J. C. Koningsberger, and M. J. T. M. Mol, "Clinical experience with simvastatin compared with cholestyramine," Drugs, vol. 36, no. 3, pp. 87-92, 1988.

[50] H. Danielsson and B. Gustafsson, "On serum-cholesterol levels and neutral fecal sterols in germ-free rats. Bile acids and steroids 59," Archives of Biochemistry and Biophysics, vol. 83, no. 2, pp. 482-485, 1959.

[51] N. M. Delzenne, P. D. Cani, and A. M. Neyrinck, "Therapeutic microbiology: probiotics and related strategies," in Prebiotics and Lipid Metabolism, chapter 14, pp. 183-192, ASM Press, Herndon, Va, USA, 2008.

[52] M. Vijay-Kumar, J. D. Aitken, F. A. Carvalho et al., "Metabolie syndrome and altered gut microbiota in mice lacking toll-like receptor 5," Science, vol. 328, no. 5975, pp. 228-231, 2010.

[53] I. Martinez, G. Wallace, C. Zhang et al., "Diet-induced metabolic improvements in a hamster model of hypercholesterolemia are strongly linked to alterations of the gut microbiota," Applied and Environmental Microbiology, vol. 75, no. 12, pp. 4175-4184, 2009.

[54] J. Z. Xiao, S. Kondo, N. Takahashi et al., "Effects of milk products fermented by Bifidobacterium longum on blood lipids in rats and healthy adult male volunteers," Journal of Dairy Science, vol. 86, no. 7, pp. 2452-2461, 2003.

[55] Food and Agriculture Organization of the United Nations, "FAO technical meeting on prebiotics," Journal of Clinical Gastroenterology, vol. 42, supplement 3, pp. S156-S159, 2007.

[56] G. R. Gibson and M. B. Roberfroid, "Dietary modulation of the human colonic microbiota: introducing the concept of prebiotics," Journal of Nutrition, vol. 125, no. 6, pp. 14011412, 1995.

[57] R. A. Rastall, "Functional oligosaccharides: application and manufacture," Annual Review of Food Science and Technology, vol. 1, no. 1, pp. 305-339, 2010.

[58] P. Sharma, B. C. Sharma, V. Puri, and S. K. Sarin, "An openlabel randomized controlled trial of lactulose and probiotics in the treatment of minimal hepatic encephalopathy," European Journal of Gastroenterology and Hepatology, vol. 20, no. 6, pp. 506-511, 2008.

[59] A. Bezkorovainy, "Probiotics: determinants of survival and growth in the gut," American Journal of Clinical Nutrition, vol. 73, no. 2, pp. S399-S405, 2001.

[60] K. M. Tuohy, G. C. M. Rouzaud, W. M. Bruck, and G. R. Gibson, "Modulation of the human gut microflora towards improve health using prebiotics-assessment of efficacy," Current Pharmaceutical Design, vol. 11, no. 1, pp. 75-90, 2005.

[61] G. R. Gibson, E. R. Beatty, X. Wang, and J. H. Cummings, "Selective stimulation of bifidobacteria in the human colon by oligofructose and inulin," Gastroenterology, vol. 108, no. 4, pp. 975-982, 1995.

[62] Food and Agricultural Organization of the United Nations and World Health Organization, "Health and nutritional properties of probiotics in food including powder milk with live lactic acid bacteria," 2001.

[63] S. Parvez, K. A. Malik, S. A. Kang, and H.-Y. Kim, "Probiotics and their fermented food products are beneficial for health," Journal of Applied Microbiology, vol. 100, no. 6, pp. 11711185, 2006.

[64] W. Krasaekoopt, B. Bhandari, and H. Deeth, "The influence of coating materials on some properties of alginate beads and survivability of microencapsulated probiotic bacteria," International Dairy Journal, vol. 14, no. 8, pp. 737-743, 2004.

[65] W. Ding and N. Shah, "Acid, bile, and heat tolerance of free and microencapsulated probiotic bacteria," Journal of Food Science, vol. 72, no. 9, pp. M446-M450, 2007.

[66] K.-Y. Lee and T. R. Heo, "Survival of Bifidobacterium longum immobilized in calcium alginate beads in simulated gastric juices and bile salt solution," Applied and Environmental Microbiology, vol. 66, no. 2, pp. 869-873, 2000.

[67] P. Capela, T. K. C. Hay, and N. P. Shah, "Effect of cryoprotectants, prebiotics and microencapsulation on survival of probiotic organisms in yoghurt and freeze-dried yoghurt," Food Research International, vol. 39, no. 2, pp. 203-211, 2006.

[68] P. Muthukumarasamy and R. A. Holley, "Survival of Escherichia coli O157:H7 in dry fermented sausages containing micro-encapsulated probiotic lactic acid bacteria," Food Microbiology, vol. 24, no. 1, pp. 82-88, 2007.

[69] V. Chandramouli, K. Kailasapathy, P. Peiris, and M. Jones, "An improved method of microencapsulation and its evaluation to protect Lactobacillus spp. in simulated gastric conditions," Journal of Microbiological Methods, vol. 56, no. 1, pp. 27-35, 2004.

[70] S. Mandal, A. K. Puniya, and K. Singh, "Effect of alginate concentrations on survival of microencapsulated Lactobacillus casei NCDC-298," International Dairy Journal, vol. 16, no. 10, pp. 1190-1195, 2006.

[71] C. S. Favaro-Trindade and C. R. F. Grosso, "Microencapsulation of L. acidophilus (La-05) and B. lactis (Bb-12) and evaluation of their survival at the $\mathrm{pH}$ values of the stomach and in bile," Journal of Microencapsulation, vol. 19, no. 4, pp. 485-494, 2002. 
[72] A. M. Liserre, I. R. Maria, and D. G. M. Bernadette, "Microencapsulation of Bifidobacterium animalis subsp. lactis in modified Alginate-chitosan beads and evaluation of survival in simulated gastrointestinal conditions," Food Biotechnology, vol. 21, no. 1, pp. 1-16, 2007.

[73] J. S. Lee, D. S. Cha, and H. J. Park, "Survival of freezedried Lactobacillus bulgaricus KFRI 673 in chitosan-coated calcium alginate microparticles," Journal of Agricultural and Food Chemistry, vol. 52, no. 24, pp. 7300-7305, 2004.

[74] N. T. Annan, A. D. Borza, and L. T. Hansen, "Encapsulation in alginate-coated gelatin microspheres improves survival of the probiotic Bifidobacterium adolescentis 15703T during exposure to simulated gastro-intestinal conditions," Food Research International, vol. 41, no. 2, pp. 184-193, 2008.

[75] C. Martoni, J. Bhathena, A. M. Urbanska, and S. Prakash, "Microencapsulated bile salt hydrolase producing Lactobacillus reuteri for oral targeted delivery in the gastrointestinal tract," Applied Microbiology and Biotechnology, vol. 81, no. 2, pp. 225-233, 2008.

[76] K. Kailasapathy, "Survival of free and encapsulated probiotic bacteria and their effect on the sensory properties of yoghurt," LWT-Food Science and Technology, vol. 39, no. 10, pp. 1221-1227, 2006.

[77] K. Sultana, G. Godward, N. Reynolds, R. Arumugaswamy, P. Peiris, and K. Kailasapathy, "Encapsulation of probiotic bacteria with alginate-starch and evaluation of survival in simulated gastrointestinal conditions and in yoghurt," International Journal of Food Microbiology, vol. 62, no. 1-2, pp. 47-55, 2000.

[78] A. Homayouni, A. Azizi, M. R. Ehsani, M. S. Yarmand, and S. H. Razavi, "Effect of microencapsulation and resistant starch on the probiotic survival and sensory properties of synbiotic ice cream," Food Chemistry, vol. 111, no. 1, pp. 50-55, 2008.

[79] W. C. Lian, H. C. Hsiao, and C. C. Chou, "Survival of bifidobacteria after spray-drying," International Journal of Food Microbiology, vol. 74, no. 1-2, pp. 79-86, 2002.

[80] W. C. Lian, H. C. Hsiao, and C. C. Chou, "Viability of microencapsulated bifidobacteria in simulated gastric juice and bile solution," International Journal of Food Microbiology, vol. 86, no. 3, pp. 293-301, 2003.

[81] H. C. Hsiao, W. C. Lian, and C. C. Chou, "Effect of packaging conditions and temperature on viability of microencapsulated bifidobacteria during storage," Journal of the Science of Food and Agriculture, vol. 84, no. 2, pp. 134-139, 2004.

[82] C. L. Hyndman, A. F. Groboillot, D. Poncelet, C. P. Champagne, and R. J. Neufeld, "Microencapsulation of Lactococcus lactis within cross-linked gelatin membranes," Journal of Chemical Technology and Biotechnology, vol. 56, no. 3, pp. 259-263, 1993.

[83] M. J. Chen, K. N. Chen, and Y. T. Kuo, "Optimal thermotolerance of Bifidobacterium bifidum in gellan-alginate microparticles," Biotechnology and Bioengineering, vol. 98, no. 2, pp. 411-419, 2007.

[84] W. Sun and M. W. Griffiths, "Survival of bifidobacteria in yogurt and simulated gastric juice following immobilization in gellan-xanthan beads," International Journal of Food Microbiology, vol. 61, no. 1, pp. 17-25, 2000.

[85] L. D. McMaster and S. A. Kokott, "Micro-encapsulation of Bifidobacterium lactis for incorporation into soft foods," World Journal of Microbiology and Biotechnology, vol. 21, no. 5, pp. 723-728, 2005.

[86] L. D. McMaster, S. A. Kokott, S. J. Reid, and V. R. Abratt, "Use of traditional African fermented beverages as delivery vehicles for Bifidobacterium lactis DSM 10140," International
Journal of Food Microbiology, vol. 102, no. 2, pp. 231-237, 2005.

[87] H. Chen, W. Ouyang, M. Jones et al., "Preparation and characterization of novel polymeric microcapsules for live cell encapsulation and therapy," Cell Biochemistry and Biophysics, vol. 47, no. 1, pp. 159-167, 2007.

[88] A. C. Oliveira, T. S. Moretti, C. Boschini, J. C. C. Baliero, O. Freitas, and C. S. Favaro-Trindade, "Stability of microencapsulated B. lactis (BI 01) and L. acidophilus (LAC 4) by complex coacervation followed by spray drying," Journal of Microencapsulation, vol. 24, no. 7, pp. 673-681, 2007.

[89] S. Lahtinen, A. Ouwehand, S. Salminen, P. Forssell, and P. Myllarinen, "Effect of starch- and lipid-based encapsulation on the culturability of two Bifidobacterium longum strains," Letters in Applied Microbiology, vol. 44, no. 5, pp. 500-505, 2007.

[90] A. Picot and C. Lacroix, "Encapsulation of bifidobacteria in whey protein-based microcapsules and survival in simulated gastrointestinal conditions and in yoghurt," International Dairy Journal, vol. 14, no. 6, pp. 505-515, 2004.

[91] A. A. Reid, J. C. Vuillemard, M. Britten, Y. Arcand, E. Farnworth, and C. P. Champagne, "Microentrapment of probiotic bacteria in a $\mathrm{Ca}^{2+}$-induced whey protein gel and effects on their viability in a dynamic gastro-intestinal model," Journal of Microencapsulation, vol. 22, no. 6, pp. 603-619, 2005.

[92] K. Adhikari, I. U. Grun, A. Mustapha, and L. N. Fernando, "Changes in the profile of organic acids in plain set and stirred yogurts during manufacture and refrigerated storage," Journal of Food Quality, vol. 25, no. 5, pp. 435-451, 2002.

[93] P. Audet, C. Paquin, and C. Lacroix, "Immobilized growing lactic acid bacteria with k-carrageenan-locust bean gum gel," Applied Microbiology and Biotechnology, vol. 29, no. 1, pp. 11$18,1988$.

[94] L. A. Shackelford, D. R. Rao, C. B. Chawan, and S. R. Pulusani, "Effect of feeding fermented milk on the incidence of chemically induced colon tumors in rats," Nutrition and Cancer, vol. 5, no. 3, pp. 159-164, 1983.

[95] B. R. Goldin, L. J. Gualtieri, and R. P. Moore, "The effect of Lactobacillus GG on the initiation and promotion of DMHinduced intestinal tumors in the rat," Nutrition and Cancer, vol. 25, no. 2, pp. 197-204, 1996.

[96] J. Singh, A. Rivenson, M. Tomita, S. Shimamura, N. Ishibashi, and B. S. Reddy, "Bifidobacterium longum, a lactic acidproducing intestinal bacterium inhibits colon cancer and modulates the intermediate biomarkers of colon carcinogenesis," Carcinogenesis, vol. 18, no. 4, pp. 833-841, 1997.

[97] B. S. Reddy and A. Rivenson, "Inhibitory effect of Bifidobacterium longum on colon, mammary, and liver carcinogenesis induced by 2 -amino-3-methylimidazo[4,5-f] quinoline, a food mutagen," Cancer Research, vol. 53, no. 17, pp. 39143918, 1993.

[98] G. H. McIntosh, P. J. Royle, and M. J. Playne, "A probiotic strain of L. Acidophilus reduces DMH-induced large intestinal tumors in male sprague-dawley rats," Nutrition and Cancer, vol. 35, no. 2, pp. 153-159, 1999.

[99] H.-H. Cui, C. L. Chen, J. D. Wang et al., "Effects of probiotic on intestinal mucosa of patients with ulcerative colitis," World Journal of Gastroenterology, vol. 10, no. 10, pp. 15211525, 2004.

[100] D. Jonkers and R. Stockbrugger, "Probiotics and inflammatory bowel disease," Journal of the Royal Society of Medicine, vol. 96, no. 4, pp. 167-171, 2003.

[101] M. P. Taranto, M. Medici, G. Perdigon, A. P. Ruiz Holgado, and G. F. Valdez, "Evidence for hypocholesterolemic effect of 
Lactobacillus reuteri in hypercholesterolemic mice," Journal of Dairy Science, vol. 81, no. 9, pp. 2336-2340, 1998.

[102] J. Mohan, R. Arora, and M. Khalilullah, "Preliminary observations on effect of Lactobacillus sporogenes on serum lipid levels in hypercholesterolemic patients," Indian Journal of Medical Research, vol. 92, no. 1, pp. 431-432, 1990.

[103] A. P. Femia, C. Luceri, P. Dolara et al., "Antitumorigenic activity of the prebiotic inulin enriched with oligofructose in combination with the probiotics Lactobacillus rhamnosus and Bifidobacterium lactis on azoxymethane-induced colon carcinogenesis in rats," Carcinogenesis, vol. 23, no. 11, pp. 1953-1960, 2002.

[104] R. D. Rolfe, "The role of probiotic cultures in the control of gastrointestinal health," Journal of Nutrition, vol. 130, supplement 2, pp. S396-S402, 2000.

[105] S. F. Solga and A. M. Diehl, "Non-alcoholic fatty liver disease: lumen-liver interactions and possible role for probiotics," Journal of Hepatology, vol. 38, no. 5, pp. 681-687, 2003.

[106] VSL Pharmaceuticals, "VSL\#3 The Living Shield," 2009.

[107] K. Madsen, A. Cornish, P. Soper et al., "Probiotic bacteria enhance murine and human intestinal epithelial barrier function," Gastroenterology, vol. 121, no. 3, pp. 580-591, 2001.

[108] E. Esposito, A. Iacono, G. Bianco et al., "Probiotics reduce the inflammatory response induced by a high-fat diet in the liver of young rats," Journal of Nutrition, vol. 139, no. 5, pp. 905-911, 2009.

[109] D. Adawi, S. Ahrne, and G. Molin, "Effects of different probiotic strains of Lactobacillus and Bifidobacterium on bacterial translocation and liver injury in an acute liver injury model," International Journal of Food Microbiology, vol. 70, no. 3, pp. 213-220, 2001.

[110] D. Adawi, F. B. Kasravi, G. Molin, and B. Jeppsson, "Effect of Lactobacillus supplementation with and without arginine on liver damage and bacterial translocation in an acute liver injury model in the rat," Hepatology, vol. 25, no. 3, pp. 642647, 1997.

[111] D. Poncelet, "Microencapsulation: fundamentals, methods and applications," in Surface Chemistry in Biomedical and Environmental Science, pp. 23-34, Springer, Amsterdam, The Netherlands, 2006.

[112] R. M. Hernandez, G. Orive, A. Murua, and J. L. Pedraz, "Microcapsules and microcarriers for in situ cell delivery," Advanced Drug Delivery Reviews, vol. 62, no. 7-8, pp. 711730, 2010.

[113] S. Rokka and P. Rantamaki, "Protecting probiotic bacteria by microencapsulation: challenges for industrial applications," European Food Research and Technology, vol. 231, no. 1, pp. $1-12,2010$.

[114] W. Song, Q. He, H. Mohwald, Y. Yang, and J. Li, "Smart polyelectrolyte microcapsules as carriers for water-soluble small molecular drug," Journal of Controlled Release, vol. 139, no. 2, pp. 160-166, 2009.

[115] L. T. Hansen, P. M. Allan-Wojtas, Y.-L. Jin, and A. T. Paulson, "Survival of Ca-alginate microencapsulated Bifidobacterium spp. in milk and simulated gastrointestinal conditions," Food Microbiology, vol. 19, no. 1, pp. 35-45, 2002.

[116] W. Ouyang, H. M. Chen, M. L. Jones et al., "Artificial cell microcapsule for oral delivery of live bacterial cells for therapy: design, preparation, and in-vitro characterization," Journal of Pharmacy and Pharmaceutical Sciences, vol. 7, no. 3, pp. 315-324, 2004.
[117] H. Chen, W. Ouyang, C. Martoni et al., "Investigation of genipin cross-linked microcapsule for oral delivery of live bacterial cells and other biotherapeutics: preparation and in vitro analysis in simulated human gastrointestinal model," International Journal of Polymer Science, vol. 2010, no. 1, pp. 1-10, 2010.

[118] S. Prakash and T. M. S. Chang, "Microencapsulated genetically engineered E. coli DH5 cells for plasma urea and ammonia removal based on : 1. Column bioreactor and 2 . Oral administration in uremic rats," Artificial Cells, Blood Substitutes, and Immobilization Biotechnology, vol. 24, no. 3, pp. 201-218, 1996.

[119] S. Wee and W. Gombotz, "Protein release from alginate matrices," Advanced Drug Delivery Reviews, vol. 31, no. 3, pp. 267-285, 1998.

[120] A. Haug and B. Larsen, "Quantitative determination of the uronic acid composition of alginates," Acta Chemica Scandinavica, vol. 16, no. 8, pp. 1908-1918, 1962.

[121] J. W. Anderson and S. E. Gilliland, "Effect of fermented milk (yogurt) containing Lactobacillus acidophilus L1 on serum cholesterol in hypercholesterolemic humans," Journal of the American College of Nutrition, vol. 18, no. 1, pp. 43-50, 1999.

[122] J. Bhathena, C. Martoni, A. Kulamarva, A. M. Urbanska, M. Malhotra, and S. Prakash, "Orally delivered microencapsulated live probiotic formulation lowers serum lipids in hypercholesterolemic hamsters," Journal of Medicinal Food, vol. 12, no. 2, pp. 310-319, 2009.

[123] B. L. Pool-Zobel, C. Neudecker, I. Domizlaff et al., "Lactobacillus- and bifidobacterium-mediated antigenotoxicity in the colon of rats," Nutrition and Cancer, vol. 26, no. 3, pp. 365380, 1996.

[124] I. de Smet, L. van Hoorde, N. de Saeyer, M. Vande Woestyne, and W. Verstraete, "In vitro study of bile salt hydrolase (BSH) activity of BSH isogenic Lactobacillus plantarum 80 strains and estimation of cholesterol lowering through enhanced BSH activity," Microbial Ecology in Health and Disease, vol. 7, no. 6, pp. 315-329, 1994. 

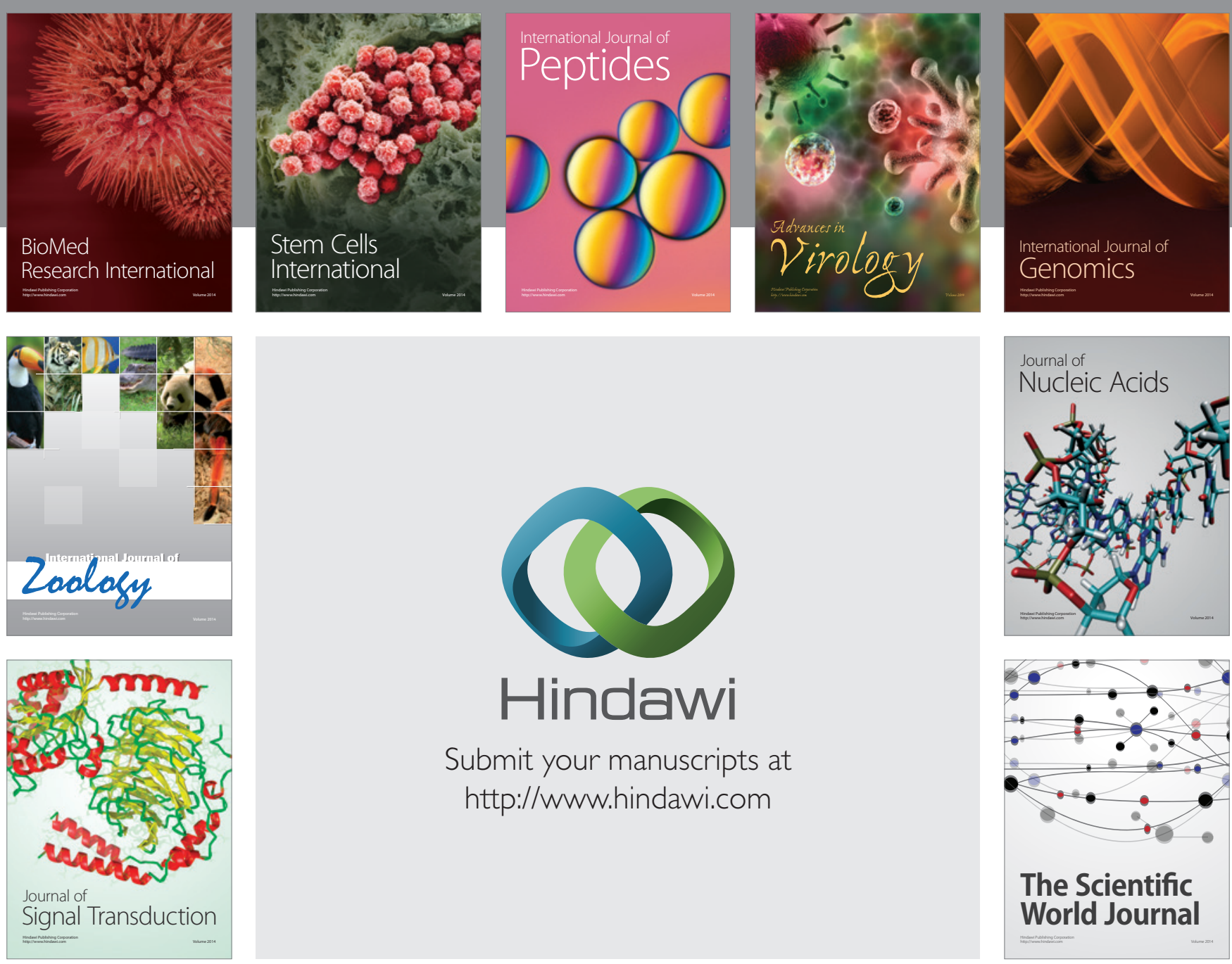

Submit your manuscripts at

http://www.hindawi.com
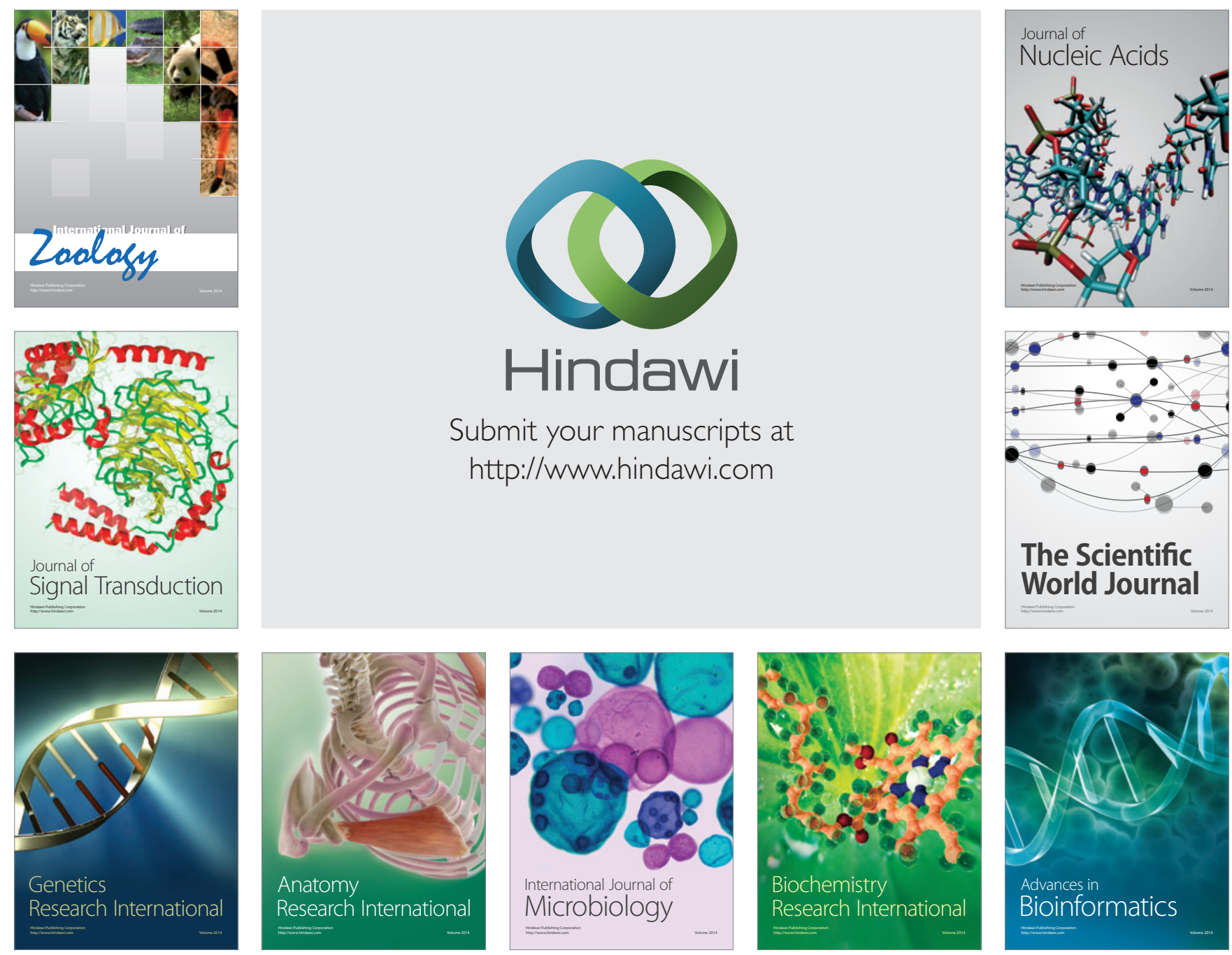

The Scientific World Journal
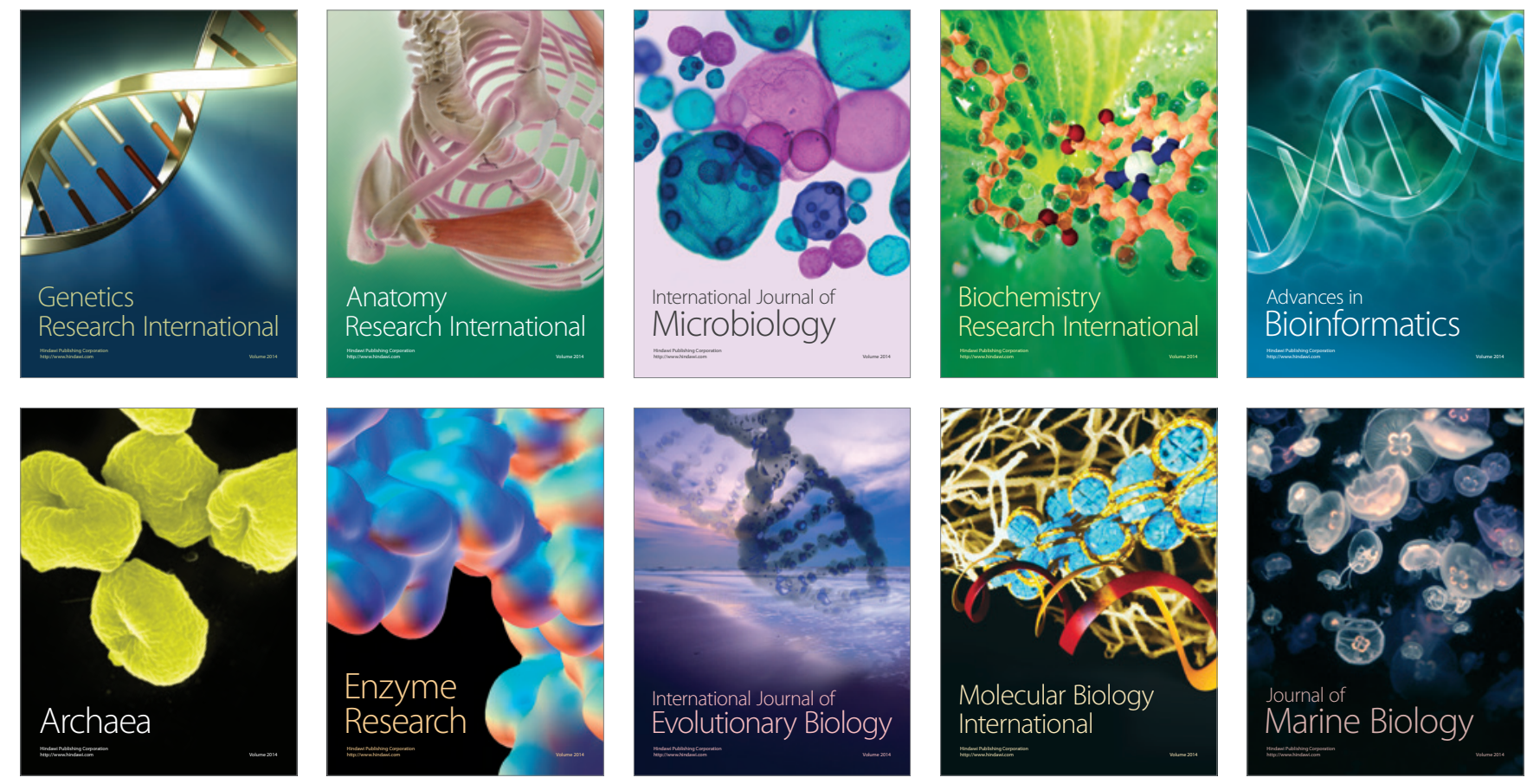